\title{
BRAÇOS PARA TODA OBRA? OS HAITIANOS E O MERCADO DE TRABALHO NO AMAZONAS $^{1}$
}

Sidney Antônio da Silva ${ }^{2}$

\begin{abstract}
Resumo: Este artigo tem como objetivo analisar a relação entre imigração e mercado de trabalho, tomando como referência os haitianos que vivem em Manaus. Partindo da perspectiva de análise que aborda o imigrante como um "trabalhador temporário", pretende-se sinalizar os limites dessa definição e suas implicações para o exercício da cidadania, já que ela o reduz o imigrante à condição de "força de trabalho" e não o reconhece enquanto sujeito de direitos.
\end{abstract}

Palavras chave: Haitianos. Mercado de trabalho. Cidadania.

\begin{abstract}
This article aims to analyze the relationship between immigration and the labor market, taking as reference the Haitians who live in Manaus. Based on the analysis that addresses the immigrant as a "temporary worker", is intended to show the limits of this definition and its implications for the exercise of citizenship, as it reduces the immigrant to the condition of "workforce" and not recognizes him as a subject of rights.
\end{abstract}

Keywords: Hatians. Labor market. Citizenship.

A migração, entendida como um "fato social total", coloca em movimento as sociedades envolvidas nesse fenômeno, pois aquele que emigra torna-se um imigrante, tão logo cruze as fronteiras do país de "destino" ou de passagem. Essa dupla pertença sinaliza a ambiguidade presente na condição do imigrante, a de "ser ignorada enquanto provisória, ao mesmo tempo, não se confessar enquanto transplante definitivo" (SAYAD, 1998, p. 46). Nessa perspectiva, o imigrante é definido pelo mercado de trabalho, como um "trabalhador temporário", pois, uma vez terminada a sua missão laboral, deveria retornar a seu país de origem. Essa definição enseja uma série de implicações para os imigrantes, já que ela os reduz à condição de "força de trabalho" e não os reconhece enquanto sujeitos de direitos. É com base nesse enfoque que pretendemos abordar a relação entre migração e

Trabalho apresentado na $29^{\mathrm{a}}$ Reunião Brasileira de Antropologia, realizada entre os dias 03 e 06 de agosto de 2014, Natal/RN, com o apoio do Conselho Nacional de Desenvolvimento Científico e Tecnológico - CNPq.

Antropólogo e professor do Departamento e Programa de Pós-Graduação em Antropologia Social da Universidade Federal do Amazonas - UFAM. Coordena o Grupo de Estudos Migratórios na Amazônia- GEMA e a rede Migrações no Brasil Contemporâneo, do Instituto Brasil Plural (INCT/CNPq). E-mail: sidsilva@ufam.edu.br 
trabalho, tomando como exemplo o caso dos haitianos em Manaus.

A chegada desses imigrantes na cidade, a partir de 2010, foi tomada inicialmente como algo que poderia ser passageiro, pois os grandes centros urbanos que eles mencionam e para onde pretendem ir, estão localizados há milhares de quilômetros de Manaus, ou seja, nas Regiões Centro-Oeste, Sudeste e Sul. Contudo, dos mais de oito mil haitianos que já passaram pela cidade, segundo estimativas da Pastoral do Migrante, cerca de dois mil continuam tentando se inserir nela, tanto laboral quanto socialmente. Os dados aqui analisados foram coletados mediante entrevistas realizadas em diferentes momentos e lugares, durante os anos de 2012 e 2013, em Brasiléia (AC) e na cidade de Manaus (AM), em 2014.

\section{Haitianos em Manaus: Perfil e inserÇão laboral}

Segundo a Pastoral do Migrante de Manaus, até maio de 2014, já haviam passado pela capital amazonense mais de dez mil haitianos, dos quais cerca de dois mil ainda estariam vivendo na cidade. Os demais seguiram viagem para outros estados brasileiros, entre eles Paraná, São Paulo, Rio Grande do Sul, Santa Catarina, Rio de Janeiro, Minas Gerais, Goiás, Mato Grosso e Amapá ${ }^{3}$, entre outros. Dados do Sistema Nacional de Cadastramento e Registro de Estrangeiros/DPF (SINCRE) apontam para a presença de 1.495 haitianos(as) em Manaus, no período de 01/01/2010 a 20/ 03/2014. Com relação ao local de entrada, a maioria, 1.132, passou por Tabatinga. Entretanto, chama a atenção o fato de que 242 tiveram como entrada a cidade de Manaus, o que poderia sugerir a sua chegada por via aérea. Contudo, é sabido que muitos não esperavam para serem atendidos em Tabatinga, em razão da longa espera, e seguiam até Manaus sem nenhum documento, onde se apresentavam a um agente da Polícia Federal local. Outro dado que chama a atenção é que 34 entraram por São Paulo e depois vieram para Manaus, certamente, em razão das redes sociais e migratórias. O mesmo motivo pode ser atribuído a dois haitianos que vieram de Porto Alegre e a outros dois do Rio de Janeiro. Vale lembrar, porém, que tais dados devem ser tomados como um indicativo dessa presença em Manaus, já que muitos passaram por ela e já estão em outras regiões do Brasil, apontando para uma circularidade desses imigrantes no país.

Em geral eles são jovens, dentro de uma faixa etária que vai dos vinte aos quarenta anos de idade, na sua maioria do sexo masculino, solteiros e com uma escolaridade média. Parte deles apresenta uma formação de nível

\footnotetext{
$\mathrm{Na}$ Amazônia, outras duas cidades que registram a presença de haitianos, segundo dados do SINCRE, são Porto Velho (RO), com 765 registros e Macapá (AP), com 429. A significativa presença nesta última cidade pode estar relacionada ao fato de que ela está na rota daqueles que pretendem ir à Guiana Francesa e, em razão do controle da entrada naquele país, acabam ficando em Macapá ou migrando para outras cidades brasileiras.
} 
técnico e uma minoria tem curso universitário completo (SILVA, 2012, p. 310). Como qualquer outro fluxo de migração laboral, num primeiro momento, destaca-se a presença quase exclusiva de homens, fato que começa a mudar, à medida que a rede social se amplia e se consolida. Num segundo momento, vem a presença de mulheres que se denominam solteiras, porém, afirmam ter filhos que ficaram no Haiti. Outras trouxeram seus filhos ou emigraram grávidas, tendo nascido seus filhos no Brasil. A presença de grupos familiares completos também tem aumentado entre eles, mediante os processos de reunificação familiar. Contudo, um fato que tem chamado a atenção das autoridades migratórias é a presença de menores de dezoito anos sem a presença de seus respectivos genitores, fato que enseja interrogações. Seria uma forma de reunificação familiar, supondo que parte do grupo familiar já esteja no Brasil ou seria parte de estratégias familiares que delegam a guarda do menor a um parente ou amigo, na esperança que ele tenha mais oportunidades no país de imigração, como por exemplo, o acesso à educação.

Do ponto de vista da origem, inicialmente, grande parte deles eram provenientes da capital Porto Príncipe, cidade duramente afetada pelo terremoto de 2010, e outras que não sofreram danos, como Gonaives e Jacmel. Hoje é possível encontrar haitianos de diferentes localidades do Haiti, inclusive de outros países, como a República Dominicana, Equador e Venezuela. Importa lembrar, contudo, que para a maioria o lugar de nascimento não coincide com o de partida antes de vir para o Brasil, isto porque a migração interna e internacional, para países vizinhos, como é o caso da República Dominicana e Cuba, ou para os Estados Unidos, Canadá e França, é um fenômeno histórico que faz parte das estratégias de reprodução sócioeconômica dos haitianos (PERUSEK, 1984), num contexto mais amplo da reprodução do capital. Afinal, para Gaudemar (1977), é a mobilidade do capital que produz a mobilidade da força de trabalho.

Em Manaus, eles estão em diferentes bairros da cidade, entre eles na Zona Centro-Sul, como Chapada, São Geraldo, São Jorge, São Raimundo e outros da Zona Norte, como Manoa, Zumbi, Mutirão, Cidade Nova e da Zona Leste, como o Nova República. Em geral trata-se de casas ou quartos alugados, pequenos e pouco arejados, onde vivem várias pessoas, como uma forma de dividir os custos do aluguel. Outros continuam em abrigos mantidos pela Pastoral do Migrante e ONGs, como é o caso do projeto AMA HAITI, no bairro Parque Dez. Nesses abrigos estão aqueles que ainda não conseguiram estabilidade na cidade, mediante a inserção no mercado de trabalho.

O setor do mercado de trabalho que mais absorve trabalhadores haitianos em Manaus é o da construção civil, seguido pelos do comércio e de serviços. Não encontrando trabalho no mercado de trabalho formal, alguns são obrigados a aceitar atividades informais, como segurar placas de 
propagandas pelas ruas da cidade ou vender objetos e alimentos para os próprios haitianos. As dificuldades de encontrar trabalho se devem, em primeiro lugar, pelo refluxo do mercado de trabalho local e nacional, já que a vinda de empregadores de outros estados diminuiu em 2013 e, em segundo, pela falta de qualificação exigida pelo mercado, além do fator linguístico que dificulta a comunicação, pelo menos no momento da chegada.

Para aqueles que apresentam uma maior qualificação, o problema é encontrar trabalho em sua área, já que terão que revalidar seu diploma para exercer no Brasil a atividade laboral do país de origem. E isso é um processo demorado e custoso. Nesse caso, terão que aceitar trabalhos muito aquém de suas qualificações profissionais, configurando um desvio de função ou uma "inconsistência de status" (CAVALCANTI, 2015, p. 40). Embora o imigrante se recuse a assumir funções que exigem uma qualificação inferior a que possui, ele não terá outra opção, já que o mercado o vê como "força de trabalho" disponível e barata. Foi que o que expressou Jean, um jovem de 22 anos, que pretende continuar seus estudos no Brasil. Ele afirmou enfaticamente: "Eu não vim aqui para abrir buracos".

Para os que não concluíram seu curso, o desafio será ingressar numa universidade pública, já que na condição de imigrante terão que seguir as mesmas regras estipuladas para os brasileiros que queiram ingressar no ensino superior. A solução encontrada por eles é pagar um curso numa universidade particular, porém, nem todos conseguem um salário suficiente para se manter e estudar.

No caso das mulheres a inserção no mercado de trabalho tem sido mais difícil em razão de vários fatores, entre eles, os quais aprendizado da língua portuguesa, a baixa qualificação e a rejeição de algumas modalidades de trabalho que lhes são oferecidas, como é o caso do serviço doméstico. Uma possível explicação dessa rejeição seria, talvez, em razão dos baixos salários oferecidos e pelas exigências das empregadoras, tais como dormir no emprego e fazer horas extras, inclusive nos fins de semana. Contudo, a pouca valorização do trabalho doméstico no contexto brasileiro e o seu alto grau de informalidade, também devem ser levados em consideração.

Vindos de uma economia informal, parte dos haitianos tem dificuldade em se adaptar à legislação trabalhista brasileira e não entendem a razão de tantos descontos no valor do salário que fora combinado previamente. Decepcionados com os baixos salários, alguns abandonam o emprego, causando problemas às empresas, fator que tem contribuído para criar uma certa resistência à contratação de novos haitiano, por parte de alguns empregadores da cidade. Outro fator de rotatividade no emprego é o atraso ou o não pagamento dos salários, por parte das empresas, fato que os deixa extremamente preocupados, pois seus familiares que ficaram no Haiti esperam o envio de recursos, indispensáveis para a sua sobrevivência, num país onde a renda per capita é uma das mais baixas do continente americano, em 
torno de US\$770,95. Isso e reflete, por sua vez, no índice de desenvolvimento humano, em torno de 0,456 , colocando o Haiti no $161^{\circ}$ lugar do ranking mundial.

Contudo, diante da crescente demanda de mão-de-obra por parte de alguns setores do mercado de trabalho nacional, criam-se justificativas para contratar haitianos no lugar de brasileiros. Segundo alguns empregadores, os brasileiros "não querem trabalhar, faltam muito ao trabalho e tem vícios", como é o caso da dependência química. Já os haitianos são "dedicados ao trabalho", "de boa índole" e "aprendem rápido o idioma", pois precisam trabalhar e enviar recursos a seus familiares. $O$ fato de que grande parte deles se encontra numa situação de vulnerabilidade social, dependendo, ás vezes, da ajuda de instituições religiosas e civis para sobreviver, difundiu-se inicialmente a ideia de que eles aceitariam qualquer tipo de trabalho, particularmente aqueles que exigem grande esforço físico e pagam baixos salários. Em alguns casos o que se viu foi uma recusa desse tipo de trabalho em Manaus e a procura de outros que pagam mais e oferecem mais benefícios sociais. Por isso, a migração para o Sul e Sudeste do Brasil tem sido motivada pela perspectiva de melhores salários, além do papel das redes sociais, que acabam direcionando e alimentando os fluxos migratórios para essas regiões.

Nessa perspectiva, vale notar a mediação da Pastoral do Migrante de Manaus, a qual tem acompanhado e orientado a contratação de haitianos por empresários vindos de diferentes partes do país, particularmente do Sul. O trabalho consiste, por um lado, em orientar os imigrantes sobre os seus direitos contemplados na CLT e, por outro, cobrar dos empregadores o cumprimento dos contratos firmados. Esses vêm em busca de uma mão-deobra que já não encontram disponível em sua região, pois aqueles trabalhadores que poderiam preencher tais vagas se qualificaram e já não querem exercer atividades consideradas pesadas e insalubres, como é o caso do trabalho em frigoríficos, construção civil, limpeza urbana, entre outros. Outro setor que tem atraído parte da mão de obra haitiana é o de serviços, como é o caso da gastronomia, comércio e hotelaria. Vale notar que neste último setor, o fator linguístico tem contribuído para uma inserção mais rápida no mercado, já que parte deles fala outras línguas, além do créole e do francês.

Evitar a exploração desta mão-de-obra "disponível" tem sido uma preocupação das instituições envolvidas na acolhida dos haitianos em Manaus e em outros locais do Brasil, como é o caso de São Paulo, pois apesar de eles estarem documentados no país e terem os mesmos direitos que um trabalhador brasileiro, a própria condição de vulnerabilidade enseja a possibilidade de violações de direitos, em razão do desconhecimento da lei, bem como dos instrumentos de defesa disponíveis. Dados da Missão Paz, em São Paulo, colhidos em maio de 2014, apontam que grande parte das em- 
presas interessadas em contratar haitianos(as) não estão preocupadas em respeitar os direitos trabalhistas desses imigrantes, mas sim em maximizar seus lucros. Segundo a referida instituição de acolhida, das 482 empresas interessadas nessa mão-de-obra, apenas 78 delas preencheram os requisitos exigidos por ela para contratá-los, entre eles, pagar mais que um salário mínimo e respeitar direitos garantidos pela Consolidação das Leis do Trabalho (CLT). Isso revela que a ideia predominante de (i) migrante para grande parte dos empresários é a de um "trabalhador temporário", pronto para aceitar qualquer trabalho e sem se preocupar com as condições em que tais atividades laborais são realizadas. Afinal, na perspectiva da reprodução do capital, a única opção que lhe resta é vender a sua força de trabalho, de preferência, pelo menor custo.

Contudo, a "mediação" para o mercado de trabalho, feita pela Pastoral do Migrante, tem sido interpretada pela mídia de forma ambígua, pois uma reportagem publicada no jornal O Globo, no dia 17 de agosto de 2014, por Mariana Sanches, diz que a seleção de trabalhadores no pátio da Igreja Nossa Senhora da Paz em São Paulo, "por vezes, faz lembrar a escolha feita por senhores de engenho em mercados de escravos no Brasil, até o século XIX". Tal percepção é no mínimo, tendenciosa, pois desconhece o histórico trabalho desta Pastoral em favor dos migrantes, sobretudo nas décadas de 1970 e 1980, em momentos de cerceamento de liberdades políticas, em que o imigrante era visto pelos governos autoritários do Cone Sul, como uma possível ameaça à Segurança Nacional. Naquele contexto, a Pastoral do Migrante foi a voz dos silenciados e o lugar de encontro e recomeço para muitos deles. Hoje ela é o lugar de passagem de milhares de imigrantes que, por diferentes motivos, buscam no Brasil uma oportunidade para superar o círculo vicioso da sobrevivência.

Além de encaminhá-los para o mercado de trabalho, a Pastoral do Migrante de Manaus aposta na formação de cooperativas, como uma forma de geração de renda. Um exemplo disso é o projeto de formar uma cooperativa para a produção e venda de sorvetes pelos próprios haitianos. $\mathrm{Na}$ sede da Pastoral já há uma máquina que fabrica cerca de cem sorvetes por hora. Eles compram por vinte centavos a unidade e revendem por um real. Essa forma de empreendedorismo pode ser uma saída encontrada por eles diante da baixa absorção dessa mão-de-obra em outros setores do mercado de trabalho local. Outras iniciativas já podem ser encontradas na cidade, como Lan House e escola de idiomas voltada para brasileiros, oferecendo cursos de francês, inglês e inclusive, de créole para brasileiros.

DesaFios AO EXERCícIO DA CIDADANIA

A definição de imigrante que apontamos acima não é apenas um exercício intelectual para entender o fenômeno migratório na atualidade, 
mas a mesma tem implicações práticas na vida dos que migram, pois na condição de "trabalhadores temporários", eles não são vistos enquanto "sujeitos de direitos", mas apenas como "força de trabalho", que pode ser dispensada e renovada a qualquer momento, já que a oferta é maior que a procura. Embora no caso dos haitianos esta provisoriedade pareça não se colocar, já que eles são portadores de um visto humanitário "permanente", contudo, esse visto deverá ser renovado depois de cinco anos, deixando entrever que o "permanente" tem um caráter provisório e que a permanência deles no país dependerá de uma inserção laboral exitosa. Isso dá origem à tradicional dicotomia entre nacionais e estrangeiros, conhecida na literatura migratória como "nacionalismo metodológico". Essa perspectiva de análise não contribui para avançar na discussão de uma noção de cidadania mais ampla, que contemple, inclusive, o exercício de múltiplas cidadanias, já que naquela visão o imigrante estaria vinculado a um único Estado-nação, e a ele deve manter vinculado.

Contudo, como já não é mais possível entender a migração internacional numa perspectiva linear e temporal de origem e destino, é preciso considerar as diferentes possibilidades de circulação, envolvendo vários países e sucessivos retornos, como parte das estratégias da reprodução socioeconômica de cada imigrante ou grupo envolvido no processo migratório. Essa condição de "transnacionalidade", vivenciada pelos imigrantes internacionais, coloca uma série de questões à discussão e implementação de direitos nos contextos locais, já que o conceito de cidadania veiculado se restringe à pertença a um único Estado-nação ou a uma comunidade de estados nacionais, como é o caso da Comunidade Europeia, que classifica os que a ela não pertencem, como "extra-comunitários" e, portanto, destituídos de direitos.

No contexto brasileiro, o que se verifica é a contradição entre um marco regulatório ultrapassado e voltado para questões de "Segurança Nacional" e as exigências de respeito aos direitos humanos dos imigrantes, já garantidos, inclusive, pela Constituição Federal de 1988 e outros acordos firmados pelo Brasil em âmbito regional e internacional. Isso se reflete diretamente na forma de se lidar com a questão migratória, pois governos locais entendem que a responsabilidade pela acolhida dos imigrantes é da competência da esfera federal e, portanto, não se mobilizam para criar políticas de atendimento, alegando que os nacionais têm prioridade sobre os internacionais. $\mathrm{O}$ caso dos haitianos no Amazonas tem sido emblemático para explicitar essa contradição e, ao mesmo tempo, para evidenciar a falta de uma política migratória em âmbito nacional que articule as ações locais, tendo como preocupação a inserção sociocultural dos imigrantes, além dos processos de documentação. Isso significa que a concessão do visto "humanitário" lhes confere direitos já garantidos aos brasileiros, pelo menos em tese, como o 
direito ao trabalho, à saúde, à educação, à moradia, à livre associação e expressão de seus valores culturais.

Contudo, a igualdade entre nacionais e não nacionais, já garantida pela Constituição Federal no seu artigo $5^{\circ}$, não se aplica em sua totalidade aos imigrantes, pois aqueles que vivem no país há vários anos ou décadas, não podem votar e serem votados. Isso significa que a cidadania política lhes é negada e, como tal, continuam na condição de cidadãos de "segunda classe". Aliás, essa classificação nos remete ã histórica definição do imigrante contida no Decreto n. 9.081, de 3 de novembro de 1911, que o definia como todo aquele que acessava os portos nacionais na segunda ou terceira classe, subsidiado ou não pela União, pelos estados ou terceiros (SEYFERTH, 2001, p. 141). No caso dos haitianos, temos uma situação análoga, pois o governo do Acre subsidia o deslocamento desses imigrantes para outras cidades do Sudeste, como é o caso de São Paulo, fornecendo-lhes passagens, para quem não dispõe de recursos.

Vale notar que a dicotomia entre nacionais e estrangeiros é uma recorrência desde a primeira lei de imigração da República (Decreto 528 de 1890), passando pelo Estado Novo, com sua política seletiva e de naturalização forçada. Importa lembrar que a Constituição de 1937 substituiu o termo imigrante pelo de estrangeiro, em razão da sua conotação negativa à época. Contudo, é no Estatuto do Estrangeiro, lei 6.815 de 1980, que tal dicotomia se revela de forma ambígua e perigosa, pois, ao priorizar a "Segurança Nacional", essa lei transforma todo e qualquer estrangeiro numa possível ameaça ao Estado, particularmente os não qualificados, já que essa lei prioriza a mão-de-obra qualificada.

Com os processos de redemocratização na América Latina, essa forma de ver a migração parece ter mudado pouco, pois, ao mesmo tempo em que se defendem direitos sociais e a livre circulação de imigrantes na Região, são mantidos instrumentos de controle de entrada e de permanência fundados em princípios que privilegiam alguns grupos de imigrantes em detrimento de outros, deixando entrever que o discurso da securitização e da criminalização da migração permanece, ainda que de forma velada e ambígua nas legislações vigentes.

Propostas para a mudança da atual legislação, denominada de Estatuto do Estrangeiro (lei 6.815/1980), já foram feitas, como o projeto de lei 5655/2009, 288/2013 do Senado Federal e o anteprojeto de lei de 2014, formulado por uma comissão de especialistas, indicada pelo Ministério da Justiça. Embora a proposta de 2009 tenha incorporado a questão dos "direitos da pessoa humana" e garantias fundamentais já consagradas na Constituição brasileira, no decorrer do texto esses princípios acabam ficando obscurecidos pela preocupação com a "Segurança Nacional", limitando direitos e criando a possibilidade de criminalizar os imigrantes e suas redes, como, por 
exemplo, através da "denúncia por interesse", proposta no artigo 138. (SILVA, 2006: 162-163).

Já o projeto de lei 288/2013, o qual tramita em regime de urgência, foi proposto e aprovado pelo Senado Federal em 02 de julho de 2015 e representa um avanço em relação ao anterior, já que a política migratória brasileira deverá reger-se pelos princípios de universalidade, indivisibilidade e interdependência dos direitos humanos, pelo combate à xenofobia e pela não criminalização da imigração. Vale ressaltar que foram incluídos novos sujeitos de proteção, a saber, os indígenas, os residentes fronteiriços, asilados e apátridas, bem como cria novas políticas de vistos e residência, acrescentando, inclusive, o visto por razões humanitárias. Contudo, ele ainda mantém resquícios do já ultrapassado Estatuto do Estrangeiro ao manter no capítulo V a expressão "Do Controle Migratório", para se referir à entrada e saída de pessoas no país, denotando a ideia de perigo ou restrição a algum grupo de imigrante.

Tal ideia fica ainda mais perceptível no capitulo X, que fala das infrações e penalidades, apontando como sanção a deportação para quem entrou no território nacional sem estar autorizado ou não tenha regularizado sua situação no prazo fixado. Se tal medida visa, por um lado, coibir a imigração não documentada, por outro, ela conflita com o direito de migrar, sobretudo, para aqueles menos qualificados e em situações de vulnerabilidade. Da mesma forma, ao estabelecer como sanção multa diária e uma possível deportação para imigrantes que permaneçam no território nacional depois de esgotado o prazo de sua documentação, parece ser uma medida exagerada, que acabará penalizando aqueles que, por motivos econômicos, não tenham tido condição de renovar seus documentos. Vale notar que o valor da multa proposto pelo projeto de lei pode variar de $\mathrm{R} \$ 100$ (reais) a R $\$ 10.000$ (reais). Considerando a situação social de vulnerabilidade de grande parte dos imigrantes laborais no Brasil, a aplicação dessa sanção poderá representar uma dívida impagável, particularmente, para grupos familiares constituídos por vários membros, inviabilizando, dessa forma, seus projetos migratórios.

Embora este projeto de lei incorpore a equiparação de direitos entre imigrantes e nacionais no artigo IV, sejam eles sociais, econômicos e culturais, ele silencia em relação aos direitos políticos, entre eles o do voto, ainda que seja em âmbito local, direito, aliás, já contemplado em outros países do Mercosul. Vale lembrar, contudo, que o reconhecimento desse direito depende de uma emenda à Constituição Federal.

Caso o referido projeto seja aprovado sem alterações, outra preocupação manifesta pela Pastoral do Migrante e organizações de defesa dos direitos dos imigrantes é a extinção do Conselho Nacional de Imigração CNIg, instância que possibilita a participação de membros da sociedade 
civil, para, entre outras funções, formular a política de imigração e dirimir as dúvidas e solucionar os casos omissos na lei. $\mathrm{Na}$ atual proposta de lei não há nenhuma menção à outra instituição que faça a gestão da questão migratória no país, a não ser a Polícia Federal. Não se trata de negar a importância do trabalho dessa instituição nas fronteiras, portos e aeroportos nacionais. Contudo, é demanda histórica de imigrantes e organizações não governamentais, que o atendimento e encaminhamento de documentação dos mesmos sejam feitos por agentes civis, devidamente capacitados para este trabalho, atentando, inclusive, às suas especificidades culturais e situações de vulnerabilidade econômica e social.

A outra proposta, formulada por um grupo de especialistas em 2014, também representa um avanço em relação ao projeto $5655 / 2009$, já que incorpora contribuições de diferentes setores da sociedade civil. Tais propostas defendem que o foco central da política migratória brasileira deve estar centrada na questão dos direitos humanos. Contudo, ela ainda mantém algumas ambiguidades, já superadas pelo projeto 288/2013, como a dicotomia entre estrangeiro/imigrante; temporário/permanente; interesses nacionais/ direitos dos imigrantes. Com relação à dicotomia entre estrangeiro e imigrante é preciso deixar claro o que se entende por imigrante, pois "todo estrangeiro que transite no país" é uma definição muito ampla, esvaziando o sentido social e político da imigração, já que um turista que esteja visitando o Brasil não pode ser considerado como tal.

No caso do visto temporário ou permanente, a proposta é ainda mais contraditória, pois como pode ser considerado "permanente" um visto que tem prazo de validade especificado, ou seja, de dez anos. Nesse caso, o imigrante continuaria na condição de estrangeiro, com sua cidadania regulada, contradizendo, desta forma, o princípio de igualdade assegurado pela Constituição brasileira.

Com relação ao conceito de "interesses nacionais", o texto não especifica que interesses são esses, deixando subentendida a preocupação com a já tão criticada e temida "Segurança Nacional". Nesse caso o imigrante continuaria sendo visto como uma possível ameaça ao Estado, como já o for num passado recente.

Embora o anteprojeto incorpore a categoria imigrante nas suas dimensões sociais, culturais e econômicas, ele silencia na sua dimensão política, ou seja, o direito ao voto em nível local, aliás, uma antiga reivindicação dos imigrantes e de suas organizações, como condição para o exercício pleno da cidadania.

Outra questão ambígua do anteprojeto diz respeito ao visto humanitário, que pode ser concedido por até um ano, podendo ser prorrogado. Cabe, pois, perguntar, como seria possível aos imigrantes incluídos nessa categoria resolverem seus problemas econômicos em apenas um ano e regressarem ao seu país de origem? O visto humanitário não seria um eufemismo para se 
conceder um visto "temporário" àqueles que não são os desejáveis do ponto de vista racial e social, porém, necessários à reprodução econômica de alguns setores da economia? O caso dos haitianos parece confirmar essa hipótese.

Já no caso da integração regional, o anteprojeto propõe o "fortalecimento da integração econômica, política, social e cultural dos povos da América Latina, mediante a constituição de espaços de cidadania e de livre circulação de pessoas", o que significa um grande desafio, considerando a assimetria entre os países da região. Do ponto de vista cultural, parece que o fator linguístico ainda representa uma barreira à integração latinoamericana, pois o artigo 146 diz que "as autoridades brasileiras serão tolerantes quanto ao uso do idioma do fronteiriço e do imigrante quando se dirigirem aos órgãos ou repartições públicas (...)". Ora, a palavra "tolerante", revela, na verdade, o quanto alguns órgãos governamentais ainda são intolerantes em relação às diferenças culturais, defendendo uma homogeneidade cultural e linguística, como sinais diacríticos e incontestes da identidade nacional. Nessa perspectiva, o imigrante ainda é visto como uma possível ameaça a essa suposta "pureza" e "unidade" cultural brasileira. Durante o Estado Novo (1930-1945), por exemplo, comunidades de imigrantes eram vistas como "quistos étnicos" e, como tais, deveriam ser dissolvidas, por meio dos processos de assimilação e nacionalização.

A aceitação das diferenças não é, portanto, um processo natural e sem conflitos. Estereótipos e preconceitos são construídos particularmente em situações de crise econômica, responsabilizando o migrante pelos problemas locais, entre eles, o da falta de trabalho e do aumento da violência. Outras formas de xenofobia ganham conotações raciais, estigmatizando grupos etnicamente diferenciados, isto porque, no caso brasileiro, ainda permanece no imaginário popular a ideia de que a imigração é coisa do passado e que, em geral, ela foi bem sucedida, porque os imigrantes eram de origem europeia e, portanto, brancos. A presença dos haitianos recoloca a questão de como a sociedade brasileira lida com as relações raciais e os preconceitos de cor, uma herança nefasta de um período histórico ainda não totalmente superado.

Nessa perspectiva, uma política de respeito à diversidade cultural dos imigrantes requer ações concretas, como, por exemplo, a instituição dos "mediadores culturais", que terão como missão suscitar o debate sobre o tema, criando mecanismos de diálogo e inclusão de tais diferenças nas políticas culturais locais. Ações realizadas por diferentes grupos de imigrantes, como festivais de música, poesia e dança, feiras gastronômicas, eventos esportivos, entre outros, podem ser transformados em "pontos de cultura", inclusive com a possibilidade de se obterem recursos públicos, mediante o acesso a editais específicos. Contudo, vale lembrar que nesse processo de produção cultural o migrante não deverá ser objeto passivo de tais políticas, 
mas participante igualmente na sua elaboração e execução. Para tanto, o respeito ao direito de formar associações, bem como o de ter rádios e jornais publicados nos seus respectivos idiomas, é uma medida que viria ampliar o respeito à diversidade cultural e o exercício da cidadania. A inclusão desse direito na lei das OSCIP (lei 9.790/99), que cria a possibilidade de pessoas jurídicas (grupos de pessoas ou profissionais) de direito privado sem fins lucrativos serem qualificadas, pelo Poder Público, como Organizações da Sociedade Civil de Interesse Público, já seria um primeiro passo para superar a desconfiança em relação às organizações dos imigrantes.

No âmbito das políticas culturais, ressalta-se a importância do diálogo intercultural por meio do debate e estudo das diferenças culturais, como forma de se combater o preconceito e xenofobia, para que a cultura do "outro" não seja vista pela sociedade receptora apenas como "folclore" ou como algo "exótico", mas como algo que confere sentido aos que a praticam e que pode enriquecer aqueles que se abrem às trocas culturais. Nessa perspectiva, a migração deixaria de ser vista como um problema de segurança e de assistência social e passaria a fazer parte do processo de desenvolvimento sociocultural da sociedade brasileira.

Uma forma de se evitar a construção de preconceitos é transformar o tema das migrações numa questão de educação continuada, com campanhas de sensibilização da sociedade, bem como incluindo essa temática nos currículos do ensino médio e superior. De igual maneira essa temática deverá estar presente nos cursos de formação de agentes públicos, abarcando todos os níveis da administração pública.

Contudo, é bom lembrar que os agentes dessa inserção são os próprios imigrantes, mediante organização de forma autônoma, em vista de uma cidadania universal e plural. E, para que a garantia e ampliação de direitos deixem de ser uma retórica e passem a fazer parte das políticas locais, eles deverão ser reconhecidos enquanto sujeitos políticos, por meio do direito ao voto, pelo menos em âmbito municipal, pois é onde vivem e pagam os seus impostos. Essa é a condição sine qua non para que eles deixem de ser considerados "estrangeiros" e cidadãos de "terceira classe", para se tornarem de fato parte da sociedade brasileira.

\section{REFERÊNCIAS BIBLIOGRÁFICAS}

CAFFEU, A. P.; CUTTI, D. Só viajar! Haitianos em São Paulo: um primeiro e vago olhar. Travessia. São Paulo. n. 70, p.107-113, jan/jun, 2012.

CANCLINI, Nestor G. Las fronteras dentro de los países, las naciones fuera de su território. DIVERSITAS, n. 01, mar/set, 2013, p. 16-28. 
CAVALCANTI, Leonardo. "Imigração e Mercado de Trabalho: características e tendências". In: Cadernos OBMIGRA, V. 1, N.2, 2015, p. 35-47.

CONTINGUIBA, G. C.; PIMENTEL, M. L. Apontamentos sobre o processo de inserção social dos haitianos em Porto Velho. TRAVESSIA, n. 70, jan/jun., 2012,p. 99-106.

"Elementos etnográficos sobre a imigração na Amazônia: inserção social de haitianos em Porto Velho". In: Temas de Antropología y Migración, n. 07, , p. 31-55, diciembre 2014.

COUTO, K. C. Os desafios da sociedade cubana frente a imigração antilhana (1902-1933). (Doutorado em História), Universidade de Brasília, 2006.

FARIA, Andressa V. A diáspora haitiana para o Brasil: o novo fluxo migratório (2010-2012). Dissertação apresentada ao Programa de Pós-Graduação em Geografia - Tratamento da Informação Espacial da Pontifícia Universidade Católica de Minas Gerais. Belo Horizonte/MG, 2012.

FELDMAN-BIANCO, B. "Repensando a localidade nos estudos migratórios". In Migrações na PanAmazônia: fluxos, fronteiras e processos socioculturais. SILVA, S. A. (org). São Paulo, Hucitec/FAPEAM, 2012, p.81-92.

FERNANDES, Jéssica S. Operação Haiti: ação humanitária ou interesse político para o Brasil? . PUC Minas, Revista Conjuntura internacional, 22 de março de 2010, 1-4. (published online 22 march 2010). http:/www.pucminas.br/conjuntura. accessed 19 april 2011.

FERNANDES, Duval \& CASTRO, Maria da Consoloção G. Estudos sobre a Migração Haitiana ao Brasil e Diálogo Bilateral. Belo Horizonte, OIM/PUC, 2014.

FERNANDES, Duval; MILESI, Rosita; PIMENTA, Bruna; do CARMO, Vanessa. Migração dos haitianos para o Brasil a RN no 97/2012: uma avaliação preliminar. Cadernos de Debates Refúgio, Migrações e Cidadania, vol. 8 n 8 IMDH/ACNUR, 2013.

GAUDEMAR, Jean-Paul de. Mobilidade do trabalho e acumulação do capital. Lisboa: Editora Estampa, 1977.

GREENFIELD, S. M. Barbadian in the Brazilian Amazon. In Luso-Brazilian Review, V. 20, (1), 1983, p. 44-64.

GODOY, Gabriel G. de. "O caso dos haitianos no Brasil e a via da proteção humanitária complementar” In: RAMOS, André de Carvalho; RODRIGUES, Gilberto; ALMEIDA Guilherme Assis de (Orgs). 60 anos de ACNUR: perspectivas de futuro. São Paulo, Editora CLA Cultural, 2011.

HANDERSON, Joseph. Vodu no Haiti - Candomblé no Brasil : identidades culturais e sistemas religiosos como concepções de mundo afro-latino-americano, 2010. Dissertação (Mestrado em Ciências Sociais) - Instituto de Sociologia e Política. Universidade Federal de Pelotas, Pelotas, Rio Grande do Sul.

HARVEY, D. The condition of postmodernity. An enquiry into the origins of cultural change. (MA) Blackwell Publishers, Cambridge, Oxford, UK, 1989.

MARTin, P.; MidGley, E. e TEITElBAUM, M. Migration and development: whiter the Dominican Republic and Haiti? Center for Migration Studies of New York. International Migration Review, 36(2), summer, 2002. 
MASSEY, D et alii. Worlds in motion: understanding international migration at the end of the millennium. Clarendon, Press Oxford, 1993.

PATARRA, N. L. O Brasil: país de imigração? Metropolis, Revista eletrônica de estudos urbanos e regionais, n. 09, ano 3, 2012.

PENTINAT, Susana B. "El Estatuto jurídico de protección internacional de los refugiados ambientales". Revista Interdisciplinar da Mobilidade Humana, ano XIX, n. 36, jan./jun, 2011, p. 11-48.

PERUSEK, Glenn. "Haitian emigration in the early Twentieth Century". Internacional Migration Review, vol. XVIII, (1), 1984, p. 4-18.

ROCHA REIS, R A política do Brasil para as migrações internacionais. Contexto Internacional, vol. 33, no 1, jan-jun, 2011, p. 47-69

ROSA, Renata de Melo. "Subjetividade e inversão do racismo: um estudo de caso sobre os haitianos na República Dominicana”. Revista Interdisciplinar da Mobilidade Humana, ano XVIII, n. $34-$ Jan/jun, 2010, p. 99-112.

"Xenofobização da mulher negra migrante no processo de construção do feminino em emigração: a migração feminina haitiana em Santo Domingo". Revista Interdisciplinar da Mobilidade Humana, ano XV, n. (29), p.71-86. 2007.

RICHMAN, Karen. A more powerful sorcerer: conversion, capital, and Haitian transnational migration. New West Indian Guide. 82, (1-2), 2008.

SAYAD, A. A Imigração e os paradoxos da alteridade. São Paulo, EDUSP, 1998.

SASSEN, S. The Mobility Labor and Capital. Cambridge, Cambridge University Press, 1988.

SCHILLER, N, G. "Ethnic groups are made, not born: the Haitian immigrant and American politics". In HICKS, G. \& LEIS, P.E. (eds). Ethnics encounters. North Scituate, Mass. Duxbury Press, 1977.

SCHILLER, N. G.; BARCH, L. E BLANC, C.S. From immigrant to transmmigrant: theorizing transnational migration. Anthropological Quartely, 68(1), jan, 1995.

SEYFERTH, Giralda. "Imigração e nacionalismo: o discurso da exclusão e a política imigratória no Brasil” In Migrações Internacionais, contribuições para políticas. CASTRO, Mary G. (org.) Brasília, CNPD, 2001, p. 137-150.

SILVA, Paloma K M. Seguindo rotas: reflexões para uma etnografia da imigração haitiana no Brasil a partir do contexto de entrada pela tríplice fronteira norte. Dissertação (Mestrado em Antropologia). Departamento de Antropologia, Universidade de Brasília, 2014.

SILVA, Sidney Antônio. "Fronteira Amazônica: passagem obrigatória para os haitianos ?". In REMUHU, ano XXIII, N. 44 - jan./jun., p.119-134, 2015.

Brazil, a New Eldorado for immigrants?: The case of Haitians and the Brazilian Immigration Policy. Urbanities Journal, November, v1.2, p. 03-18, 2013.

Aqui começa o Brasil: haitianos na Triplice Fronteira e Manaus. In: SILVA, S. A. (Org.) Migrações na Pan-Amazônia - fluxos, fronteiras e processos socioculturais. São Paulo, Hucitec/ FAPEAM, 2012, p. 300-322. 
Migração Internacional recente no Amazonas: o caso dos hispanoamericanos. Contexto Internacional, vol. 33, n. 1, jan/jun, p.155-177, 2011.

Nacionalidade e etnicidade na Tríplice Fronteira Norte. Cadernos CERU, V. 19, (1), junho, p.33-48, 2008.

Bolivianos em São Paulo: entre o sonho e a realidade. Estudos Avançados 20 (57), maio/ago., p. 157-170, 2006.

SILIÉ, Rubén.. La nueva inmigración haitiana. Santo Domingo, República Dominicana: FLACSO, 2002 .

STEPICK. A.; PORTES, A. Flight into despair: A profile of recent haitian refugees in South Florida”. In Internacional Migration Review, vol. XX, (2), p. 329-350, 1986.

THOMAZ, Omar R. O terremoto no Haiti, o mundo dos brancos e o Lougawou. Novos Estudos CEBRAP, (86), p. 23-39, 2010. 